1. Auf Lebensmittel, Gesundheitspłlege, Handel etc. bezügliche. 323

\title{
Ein volumetrisches Verfahren zur Bestimmung der Salpetersäure
} im Wasser gibt $\mathrm{N}$. Kostja $\mathrm{min}^{1}$ ) an. Dasselbe beruht anf der bekannten Reaction des Brucins. Eine frisch bereitete Lösung von $0,01 \mathrm{~g}$ Brucin in $30 \mathrm{cc}$ Schwefelsäure rom specifischen Gewicht 1,837 bis 1,840 lässt man aus einer Glashahnbürette unter bestïndigem Rühren tropfenweise in $5 c c$ des zu untersuchenden Wassers einfliessen, bis eine im Anfang rasch verschwindende Röthung bleibend eintritt, und die ganze Flüssigkeit dauernd rosenroth gefärbt wird. Dem Endpunkt geht eine gelbliche Verfärbung der ganzen Flüssigkeit voraus. Der Verfasser gibt folgende empirische Tabelle.

\begin{tabular}{c|c|c|c}
\hline $\begin{array}{c}\text { Verbranchte } \\
\text { Brncin- } \\
\text { lösung }\end{array}$ & $\begin{array}{c}\text { Entsprechend } \\
\text { Salpetersäure } \\
\text { in 1 Liter } \\
\text { Wasser } \\
c c\end{array}$ & $\begin{array}{c}\text { Verbrauchte } \\
\text { Bracin- } \\
\text { lösung }\end{array}$ & $\begin{array}{c}\text { Entsprechend } \\
\text { Salpetersäure } \\
\text { in 1 Liter } \\
\text { Wasser }\end{array}$ \\
\hline \hline & $m$ & $c c$ & $m g$ \\
\hline 7,5 & 1 & 5,7 & 11 \\
6,9 & 2 & 5,6 & 12 \\
6,7 & 3 & 5,5 & 13 \\
6,5 & 4 & 5,4 & 14 \\
6,3 & 5 & 5,3 & 15 \\
6,2 & 6 & 5.2 & 16 \\
6,1 & 7 & 5,1 & 17 \\
6,0 & 8 & 5,0 & 18 \\
5,9 & 9 & 4,9 & 19 \\
5,8 & 10 & 4,8 & 20
\end{tabular}

Wasserproben, die mehr als $20 \mathrm{mg}$ Salpetersüure im Liter enthalten, sind entsprechend zu verdünnen.

Vergleichende Bestimmungen nach diesem und nach SchulzeTi i mann's Verfahren in Quell- und Brunnenwassern ergaben sehr gute Uebereinstimmung.

Eine weitere Versuchsreihe über den Einfluss von Verunreinigungen des Wassers auf das Resultat enthält grosse innere Widersprüche.

Volumetrische Bestimmung der Schwefelsäure im Trinkwasser. F. Tell $\mathrm{e}^{2}$ ) dampft $500 \mathrm{cc}$ Wasser mit 4 bis $5 \mathrm{cc}$ Salzsäure auf etwa $10 \mathrm{cc}$ ein, spält in ein $110 \mathrm{cc}$-Kölbchen, versetzt mit $10 \mathrm{cc} 1 / 10$ Normal-

1) Archiv f. Hygiene 38, 372.

2) Journ. de Pharm. et de Chim. 1898, S. 165; durch Pharm. Centralhalle 39, 190. 
Baryumchloridlösung und kocht auf. Darauf macht er mit kohlensäurefreiem Ammoniak schwach alkalisch und fügt $10 \mathrm{cc}$ einer mit der Baryumchloridlösung äquivalenten Kaliumbichromatlösung hinzu, kocht von Neuem auf und füllt nach dem Erkalten zur Marke. Man giesst dann durch ein trockenes Filter, versetzt mit $5 c c 10$ procentiger Kaliumjodidlösung: und titrirt die durch den Chromsäureüberschuss in Freiheit gesetzte Jodmenge mit 1/5 Normal-Thiosulfatlösung. 6 Molecüle $\mathrm{Na}_{2} \mathrm{~S}_{2} \mathrm{O}_{3}$ entsprechen 1 Molecül $\mathrm{K}_{2} \mathrm{Cr}_{2} \mathrm{O}_{7}$.

Bei Wasser, welches viel organische Substanzen enthält, gibt man beim Findampfen zweckmässig etwas Kaliumchlorat hinzu, muss aber dann dafür Sorge tragen, dass alles freie Chlor wieder verjagt wird.

C. Hartleb ${ }^{1}$ ) vereinfacht diese Methode, indem er den Baryumchloridüberschuss direct mit Kaliumbichromatlösung zurücktitrirt. Zur Erkennung des Endpunktes dient eine Tüpfelreaction mit Si]bernitrat als Indicator auf einer weissen Porzellanplatte. Sobald man hierbei einen deutlichen Niederschlag von schwach gelber Farbe erhält, ist der Endpunkt erreicht. Die Kaliumbichromatlosung wird auch in dieser Weise auf die Baryumchloridlösung eingestellt. Der Verfasser benutzt. 100 ce Wasser, ohne dasselbe einzudampfen.

Bestimmung der Manerfeuchtigkeit. K. B. Lehmann und Chr. Nussbaum ${ }^{2}$ ) hatten früher, gelegentlich ihrer eingehenden Studien. über das Verhalten des Kalkmörtels, insbesondere über das Trocknen desselben im Patz und in den Mauerfugen, folgende Untersuchungsmethoden angewendet. Zur Bestimmung der Feuchtigkeit brachten. sie 1,5 bis $2 g$ zerdrückte Mörtelmasse in ein Kupferschiffchen, setzten dieses in ein Glasrohr and erhitzen dasselbe unter Darchleiten von trockner, kohlensäurefreier Luft in einem Luftbade $1 \frac{1}{2}-2$ Stunden auf $105-110^{\circ} \mathrm{C}$. Der Gewichtsverlust des Schiffchen's entsprach der Feuchtigkeit. Nach dem Wägen wurde das Schiffehen in das Glasrohr, das zuvor sorgfältig von jeder Spur Beschlag gereinigt worden war, zurückgebracht und in diesem in einem schwefelsäuretrocknen Luftstrome $1 \frac{1}{4}$ bis $13 / 4$ Stunden lang stark geglüht. Die Gewichtszunahme eines vorgelegten, mit concentrirter Schwefelsäure beschickten Geisslerschen Dreikugelapparates ergibt alsdann das Hydratwasser des. Mörtels. Schliesslich wurde in einer besonders abgewogenen Probe der

1) Pharm. Zeitung 1901, S. 501; durch Pharm. Centralhalle 42, 585.

2) Archiv f. Hygiene 9, 139 u. 223. 